\title{
Evaluation of Strengthening Techniques of Traditional Masonry Buildings: Case Study of a Four-Building Aggregate
}

\author{
Romeu Vicente"; Hugo Rodrigues²; Humberto Varum³; and J. A. R. Mendes da Silva ${ }^{4}$
}

\begin{abstract}
Increasing appraisal of the durability, conservation state, and changeable use and function of old buildings in urban centers relies a great deal on the structural safety evaluation of vertical load capacity and the ability to resist horizontal forces. The need to assess seismic vulnerability, particularly of traditional masonry buildings, is a key issue. Evaluation of the seismic vulnerability of old buildings is essential in the definition of strengthening needs and minimization of damage from seismic actions in the safeguarding of built heritage. A threedimensional model was developed for an aggregate of four traditional masonry buildings located in the old city center of Coimbra, in Portugal. The finite element modeling of these buildings has aimed to identify structural fragility, understand the damages detected, and evaluate the global structural safety of these types of buildings. The primary results obtained in this case study helped to interpret the structural damage and stress distribution, and verified global stability and its consequences. Different strengthening techniques to improve the global behavior of these buildings were modeled and analyzed. A comparison of the efficiencies of strengthening strategies is also discussed. DOI: 10.1061/(ASCE)CF.1943-5509.0000164. ㅇ 2011 American Society of Civil Engineers.
\end{abstract}

CE Database subject headings: Masonry; Finite element method; Seismic effects; Aggregates; Case studies; Structural safety.

Author keywords: Old city centres; Existing masonry; Finite-element modeling; Seismic vulnerability; Dynamic behavior; Strengthening techniques.

\section{Introduction}

Old load-bearing masonry buildings exist all around the world, with special significance in historical city centers, representing the majority of the building stock. The cultural and architectural heritage value of these buildings and the consciousness of public opinion have led to a need for safeguarding and preservation policies for these architecturally valued buildings and urban aggregates.

The lack of strategies, policies, and operations by the agents responsible for this domain during the last half of the twentieth century drove the built urban stock to a situation of deep degradation in many historical centers (Vicente et al. 2005a). Even worse was the adoption of intrusive and inadequate rehabilitation and conservation practices, using new materials and construction techniques (concrete) on structural and nonstructural elements, moving away from knowledge of traditional practices and the capability and connection of solutions with the existent construction, leading to mischaracterization of the urban and patrimonial image.

${ }^{1}$ Civil Engineering Dept., Univ. of Aveiro, Campus Universitário de Santiago, 3810-193 Aveiro, Portugal (corresponding author). E-mail: romvic@ua.pt

${ }^{2}$ Civil Engineering Dept., Univ. of Aveiro, Campus Universitário de Santiago, 3810-193 Aveiro, Portugal. E-mail: hrodrigues@ua.pt

${ }^{3}$ Civil Engineering Dept., Univ. of Aveiro, Campus Universitário de Santiago, 3810-193 Aveiro, Portugal. E-mail: hvarum@ua.pt

${ }^{4}$ Civil Engineering Dept., Univ. of Coimbra, Pólo II-Pinhal de Marrocos, 3030-290 Coimbra, Portugal. E-mail: raimundo@dec.uc.pt

Note. This manuscript was submitted on April 14, 2010; approved on July 23, 2010; published online on August 2, 2010. Discussion period open until November 1, 2011; separate discussions must be submitted for individual papers. This paper is part of the Journal of Performance of Constructed Facilities, Vol. 25, No. 3, June 1, 2011. CASCE, ISSN 0887-3828/2011/3-202-216/\$25.00.
The built urban stock of the historical city center of Coimbra is essentially constituted of buildings dating from the eighteenth to the midtwentieth century (after the 1755 Lisbon earthquake), most of these built without any earthquake-resistant criteria (without any specific construction rules). Even the later constructions do not follow the seismic resisting system gaiola pombalina, developed after the Lisbon earthquake in either appropriate construction rules or techniques.

In areas prone to seismic action (Central and Southern Portugal), the need to take preventive measures of structural strengthening to minimize damages or avoid losses of incalculable value is surely a priority. Such measures require a previous evaluation of the expected seismic response through modeling representative buildings of this type of construction. The concern about structural safety under seismic actions has led to assessment of seismic vulnerability, which should be a priority in the mitigation of seismic risk and the planning and development of strengthening intervention strategies with appropriate technical decisions and financial support.

The case studied in this paper is an aggregate of four buildings that typically represent the constructive typology and constitution of the old masonry buildings in Coimbra, Portugal. This paper provides information on the constructive and structural details of the old buildings in the old city center of Coimbra and discusses their seismic and dynamic behavior, identifying structural fragility and consequently their vulnerability. It also analyses the efficiency of three commonly adopted strengthening schemes.

\section{Building Description and Structural Typology}

The city center of Coimbra is undergoing a renewal and rehabilitation process supported by a collaborative framework between the local authorities (city council) and the University of Coimbra (Vicente et al. 2005b). The four-building aggregate studied is 


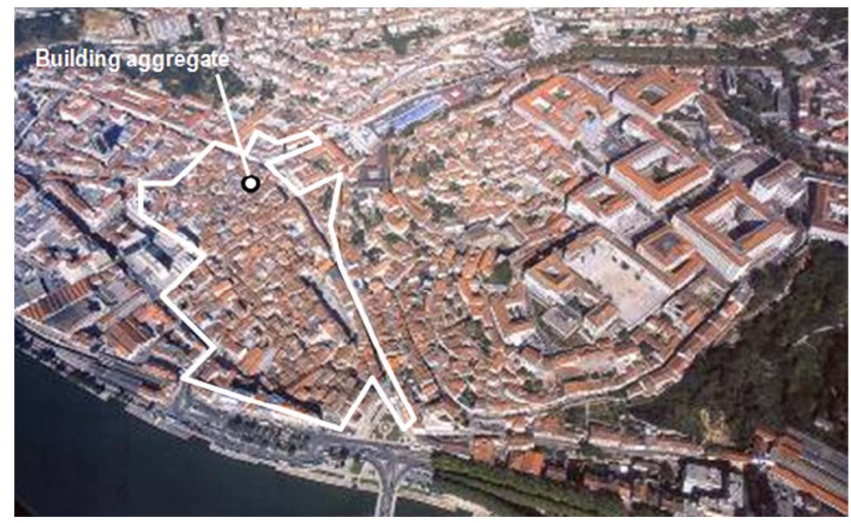

Fig. 1. Perimeter of the old city center and building aggregate studied

included in the irregular urban mesh of the old city center of Coimbra (Fig. 1).

The aggregate studied is representative of the typical architectural aspects (unidirectional staircases, stone framing, and window glazing characteristics) which provide evidence that these buildings belong to the period between the eighteenth and nineteenth centuries (Fig. 2).

An important concern is that these types of buildings do not have independent structural behavior, given that they share midwalls with adjacent buildings, interacting among themselves, therefore, their structural performance should be studied at the level of the aggregate and not for each isolated building. The evolution of the urban layout is an important issue because of the chronological construction process in which adjacent buildings share load bearing masonry walls and others use existing masonry and partition walls for floor and roof support.

This aspect is important not only for vertical load bearing capacity, but also for seismic actions, and hence seismic vulnerability. Most of the row buildings lack good connections between walls, particularly at wall corner angles. Cracking and collapse of the front and back façades during earthquakes is the most frequent failure system caused by this fragility.

According to a geotechnical site characterization report, the four buildings are constructed on horizontal silty clay and sand soil layers with some gravel and filling material. Each of these buildings has an approximately rectangular plan, with the exception of building $E_{4}$, located in the northwest corner of the group, which possesses a trapezoidal shape.

The geometry of the aggregate is irregular in height; buildings $E_{1}$ and $E_{2}$ (in the southeast quadrant) are constituted of a ground floor, two elevated floors, and an attic. Buildings $E_{3}$ and $E_{4}$ are composed of a ground floor, three elevated floors, and an attic. These buildings have no basement, because the major area of this part of the historical center of the town is quite close to the river. The dimensions and nobility of buildings are ruled by the architectural typology and traditional construction techniques. With respect to housing buildings, very simple structural schemes are observed: load-bearing external stone masonry walls and wooden floor slabs (Fig. 3).

In the majority of buildings that were inspected, particularly these four buildings, the systematic use of wood was observed in structural elements of floors, roofing structures, floor coverings, and interior partition walls. Mainly, the abundant use of dolomitic limestone was registered in external load-bearing walls, and the wall thickness varies, normally, in height from a mean value of

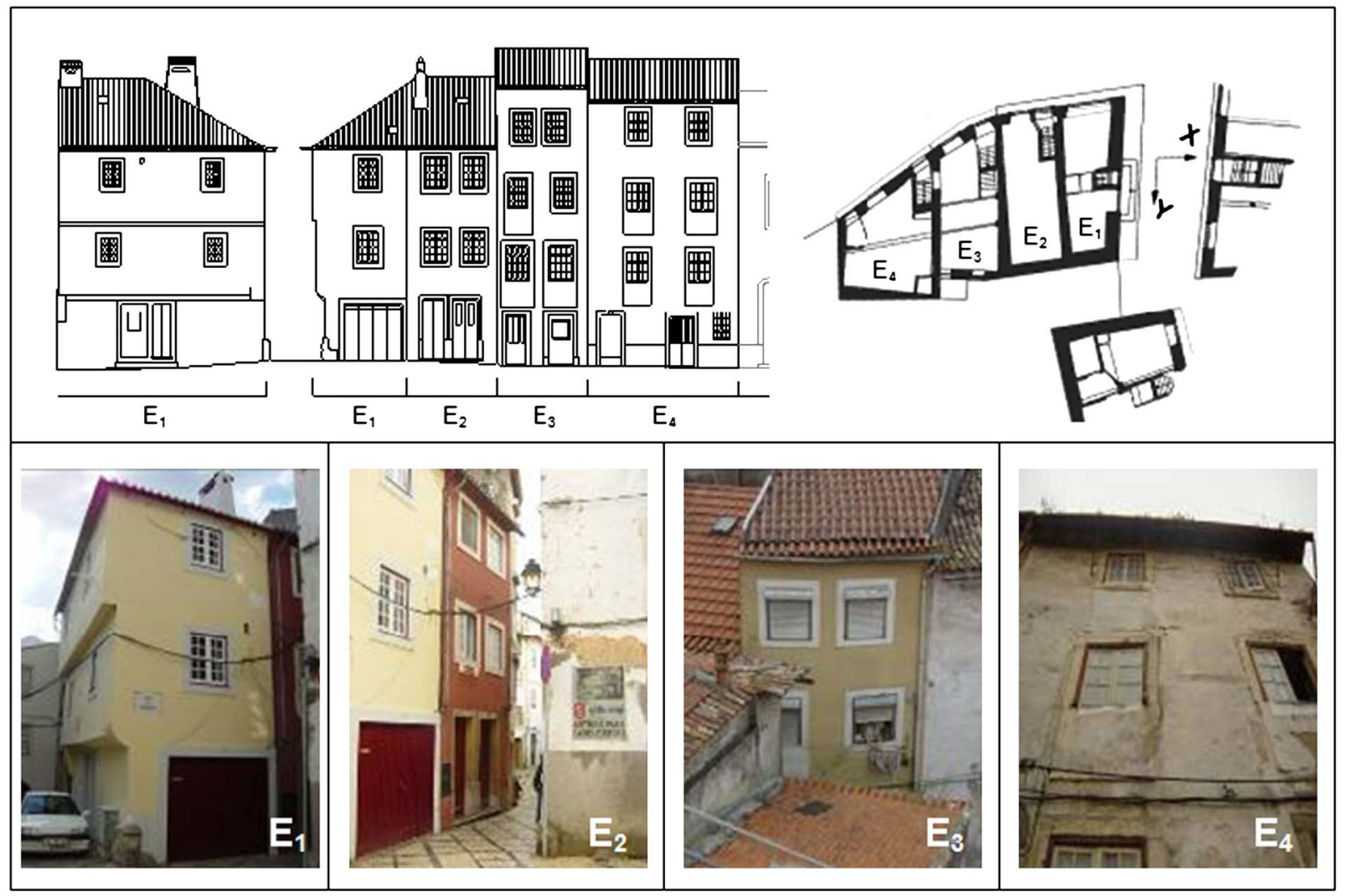

Fig. 2. Building drawings and layout; building facade of the four buildings studied 


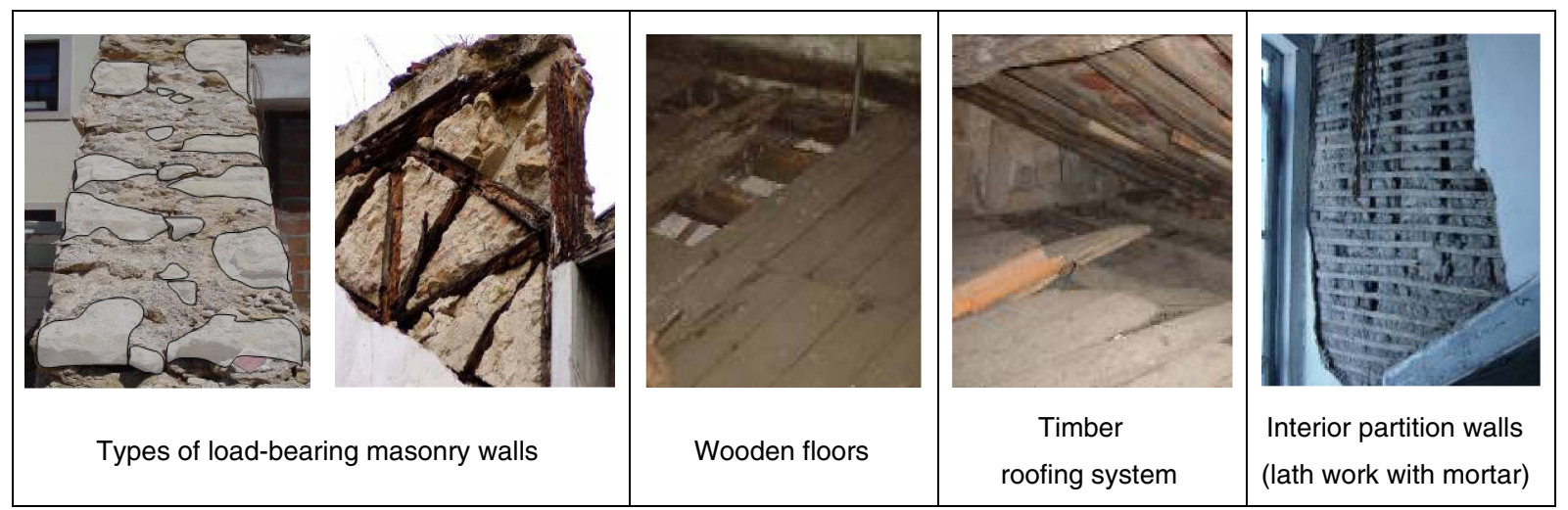

Fig. 3. Construction details of old housing

$50 \mathrm{~cm}$ (at ground level) to $26 \mathrm{~cm}$ at roof level. The use of river sand for bed joints and external mortar renderings is also very common. In most cases, roofs are covered with clay tiling. Window sashes are predominantly wooden with simple glazing windows. Interior partition walls are thin and sometimes suffer warping, revealing some kind of structural deformation, often as a consequence of creep and aging phenomena.

The masonry walls constitute the main structural elements with the wooden floor slabs, resulting in a very simple box-type structure. The masonry fabric is composed of stones in small to medium dimensions, linked with lime and clay mortar. Some of the thinner masonry (near openings and staircase structures) incorporates timbered crossed elements. These stone masonry walls are expected to have a globally good behavior in compression, usually induced by gravity forces and not by flexural, shear, or tensile actions. The weak shear and tensile strength depend on the geometric characteristics of the masonry and its components, their connection, and the material characteristics (stone size, masonry arrangement and stone laying, type of transversal connection between wall faces, type of natural stone, and type of mortar).

The floors are considered as flexible diaphragms with small beams and joists with sections of $0.10 \times 0.20 \mathrm{~m}^{2}$ placed perpendicular to the midwalls (parallel to the façades). The wood frequently used is national pitch-pine wood and, in some cases, oak and chestnut. The timber floors contribute to increasing the global stiffness of the buildings, primarily in the direction of the timber framework, contributing to the resistance to horizontal actions in that direction. Hence, the floor diaphragms possess a weak axial rigidity to distortion.

The roofs are typically sloped in two directions, and the timber roofing structure is composed of timber elements of $0.10 \times$ $0.16 \mathrm{~m}^{2}$ for rafters and beams and $0.12 \times 0.20 \mathrm{~m}^{2}$ for the roof ridge beam. These roofs exert an outward thrust on the supporting walls and others are framed to give a vertical resultant reaction. Only one of the buildings has a timber framed truss.

\section{Numerical Modeling}

The four-building aggregate was modeled with a finite-element tool to understand the dynamic behavior of these old constructions. The results of these models will aid in the identification of fragile areas (Varum and Rodrigues 2005) of the buildings and in the vulnerability evaluation of the aggregate. This numerical analysis intends (1) to estimate the natural frequencies and vibration modes for the original structure and for different strengthening solutions; and (2) to understand the seismic behavior and assess the seismic safety of the structure through global results in terms of horizontal displacements, drifts, and stresses for the different strengthening solutions.

\section{Definition of the Finite Element Global Model and Material Properties}

The structural model to simulate the behavior of the group of buildings was developed using the finite-element program Robot Millenium v17.5 (Robot Millenium v17.5). The structural geometry of the buildings was defined starting from computer-aided design (CAD) drawings in digital format and complemented by technical visits. The global three-dimensional structural model mesh was defined with four-node shell elements for the masonry and two-node bar elements for timber beams, joists, and rafters, as shown in Fig. 4.

The linear elastic models can supply important results for the first global evaluation of traditional structures, particularly in what concerns the identification of critical regions, and also helps in the analysis of potential causes of observed structural damages (Cardoso 2002; Cardoso et al. 2005).

A finite-element model should be capable of representing the global behavior of construction and particular regions with distinctive behavior (material connection and compatibility, linkage quality, and material). Therefore, some basic assumptions must be put forward:

- Two types of masonry materials were used; namely, one for common masonry walls and the other for the thinner stone panels (under windowpanes);
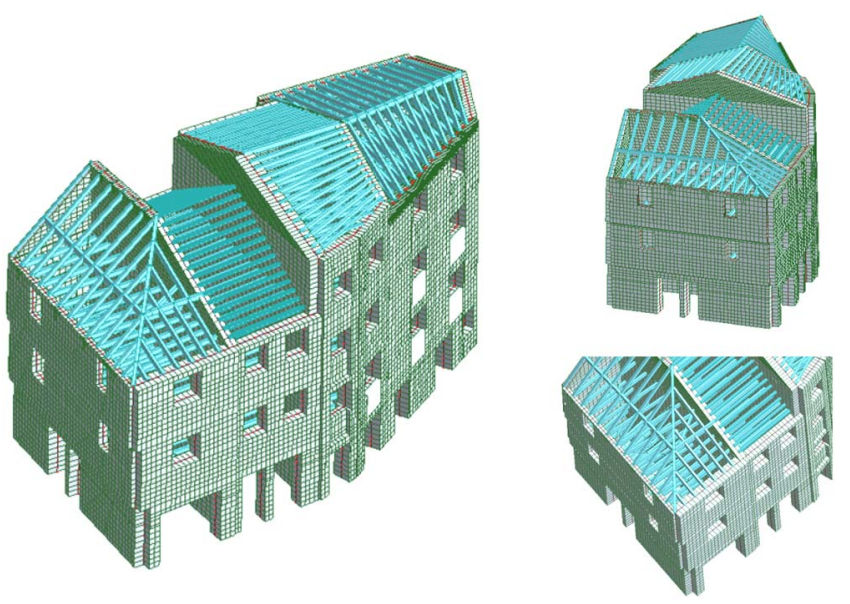

Fig. 4. Extruded three-dimensional model of the aggregate 
Table 1. Properties of the Structural Materials Considered in the Numerical Model

\begin{tabular}{|c|c|c|c|c|}
\hline Material properties & Masonry & Stone panels & Timber elements & Concrete beams \\
\hline Modulus of elasticity, $E$ (GPa) & 1.75 & 3.00 & 6.00 & 29.00 \\
\hline Material density, $\gamma\left(\mathrm{kN} / \mathrm{m}^{3}\right)$ & 19.60 & 22.00 & 6.00 & 25.00 \\
\hline Poisson ratio, $\nu$ & 0.17 & 0.30 & 0.37 & 0.20 \\
\hline Compression strength, $\sigma_{c}(\mathrm{MPa})$ & 1.00 & 3.00 & 11.00 & 17.00 \\
\hline Tensile strength, $\sigma_{t}(\mathrm{MPa})$ & 0.05 & 0.05 & 16.50 & 2.50 \\
\hline Shear strength, $\tau u(\mathrm{MPa})$ & 0.06 & 0.05 & 2.00 & - \\
\hline
\end{tabular}

Note: Value validated by the dynamic identification tests.

- The floor joists were modeled with hinges at the connection to the masonry walls but with continuity restraining the out-ofplane movement of the masonry walls connected to them;

- The roof structure was considered in the model by bar elements;

- All materials were considered to have linear elastic behavior;

- There are rigid support conditions at all points at the base of the walls, restraining the displacements in the three directions of these points. This assumption was made on the basis of a condition of fair quality of the foundations;

- A behavior factor equal to 1 was assumed, corresponding to a situation of unavailable ductility and energy dissipation capacity; and

- The roof structure system of Building $E_{2}$ (Fig. 2) was rehabilitated in the last decade and is composed of precast concrete beams.

Regarding structural elements, representative values collected from the literature were used for timber and stone masonry mechanical properties (Pagaimo 2004; Farinha and Reis 1998). The mechanical properties of the materials adopted in this analysis are listed in Table 1.

\section{Loading Conditions and Seismic Action}

Concerning the static loading conditions, self-weight (masonry walls, timber members, coverings, and interior partition walls) was contemplated for the permanent loads $\left(G_{k}\right)$; for the live load $\left(Q_{k}\right), 2.00 \mathrm{kN} / \mathrm{m}^{2}$ was considered, and $1.00 \mathrm{kN} / \mathrm{m}^{2}$ for roofing structures. For the modal analysis performed, the mass was obtained through the serviceability limit state combination $\left(1.00 \cdot G_{k}+1.00 \cdot \psi_{2} \cdot Q_{k}\right.$, with $\left.\psi_{2}=0.30\right)$.

To evaluate the seismic behavior of the building aggregate, a spectral analysis was performed considering the seismic action through a response spectrum, acting along the two independent horizontal directions. The acceleration spectrum used is based on Eurocode 8 (CEN 2004), and is in accordance with the ground type and seismic zones defined in the national annex (Carvalho 2007), considering the maximum values as a function of the reference ground acceleration and the frequency of the structure, given by the response spectrum for Type II (Zone 4) and Type I (Zone 6), Soil Type C, and 2\% damping, as presented in Fig. 5.

\section{Strengthening Techniques}

Retrofitting and structural strengthening schemes to enhance the seismic response of masonry buildings should improve global structural behavior and respect the original building materials and techniques (Giuffrè 2000).

This numerical study was also oriented toward evaluating possible strengthening solutions. Three strengthening solutions to reduce seismic vulnerability that are adequate for this type of construction were analyzed: timber structure floor stiffening, tie-rods, and stone masonry strengthening and consolidation.

The least intrusive rehabilitation scheme proposed introduces tie-rods at floor level and roof ridge level to retain and prevent the action of out-of-plane mechanisms of the façade, gable, and midwalls and to transfer the inertial forces, using 25-mm-diameter steel tie-rods [Fig. 6(a)]. The steel tie-rods were modeled as truss elements only with tensile strength (nonlinear material behavior), with the characteristics indicated in Table 2. Two tie-rod configurations were studied; however, the second configuration was revealed to be more efficient in terms of the out-of-plane deformation of walls, with anchoring to more rigid areas of the building aggregate [Fig. 6(a)].

A possible action to improve the global behavior of the structure is floor stiffening. The in-plane stiffening of the timber floor diaphragms was modeled by introducing diagonal and orthogonal timber bars with similar characteristics to the original wooden slab framework, as shown in Fig. 6(b).

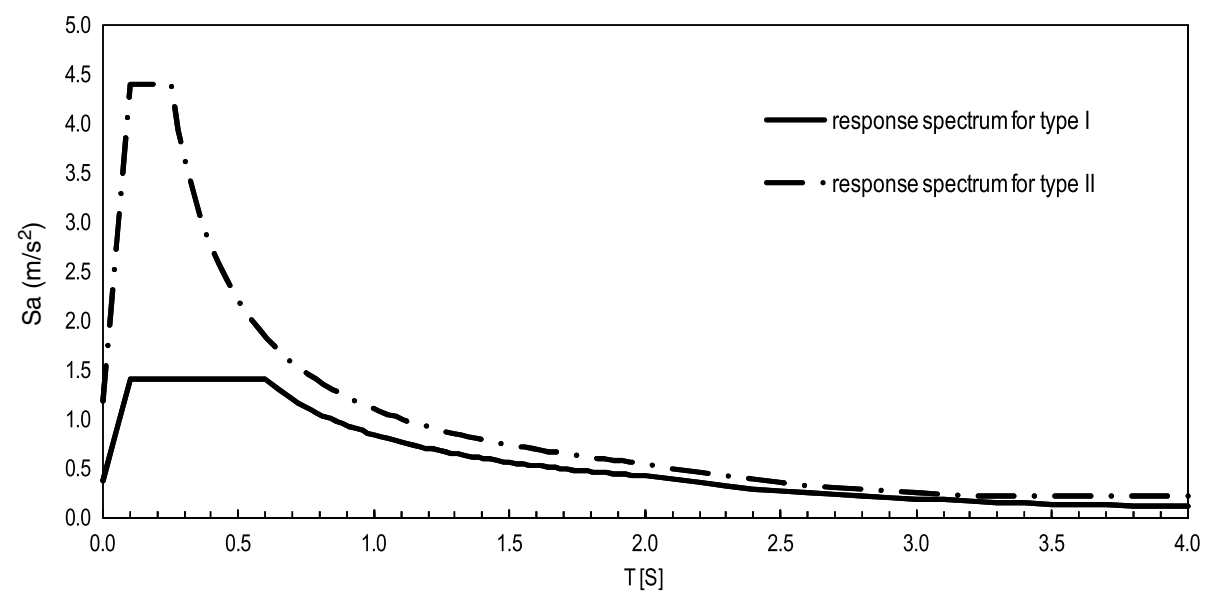

Fig. 5. Elastic response spectrum Type I and Type II for Ground Type C (CEN 2004) 


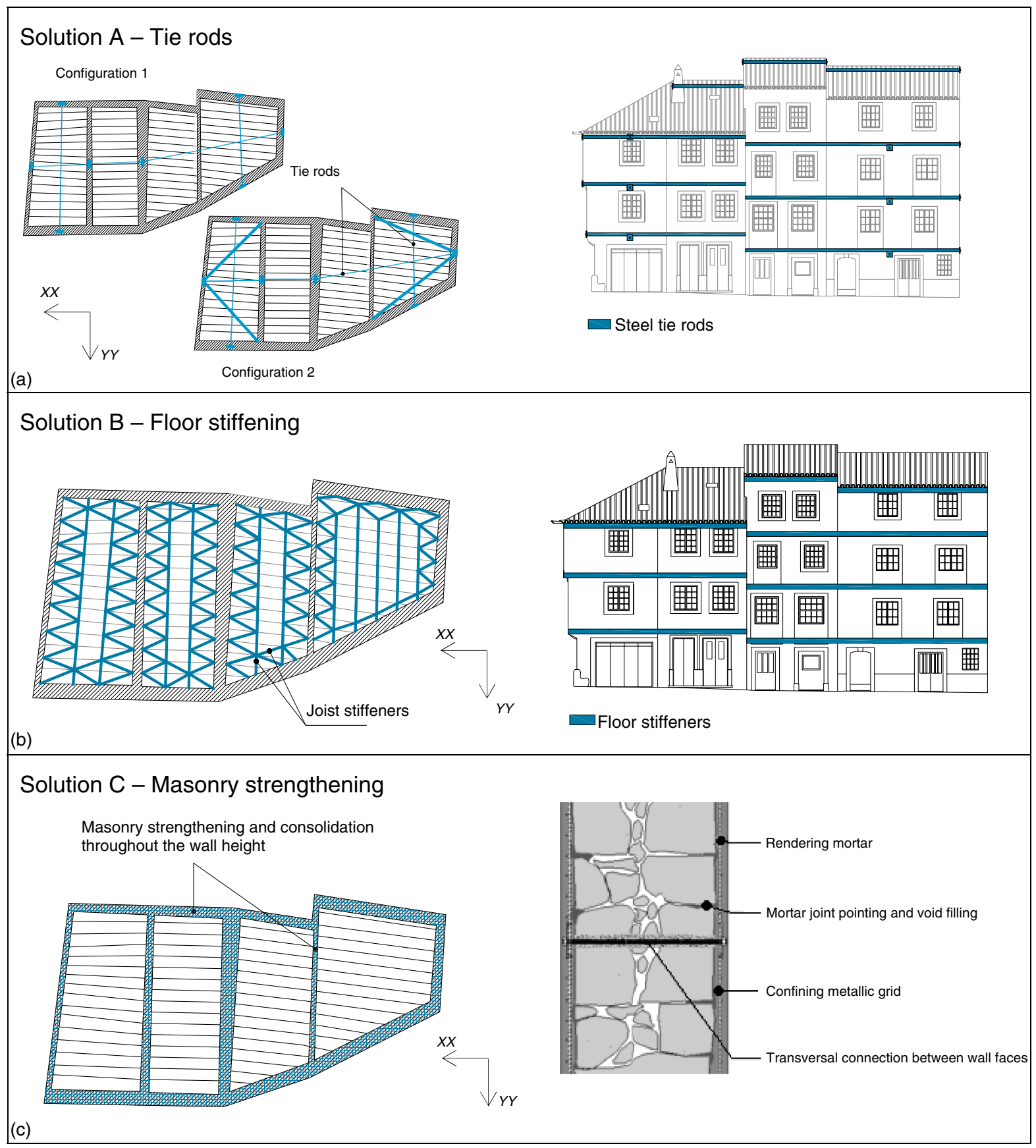

Fig. 6. Retrofitting techniques: (a) tie rods; (b) floor stiffening; (c) masonry strengthening

Taking into account that the typical stone masonry of these buildings has poor shear and flexural strength, potential wall strengthening measures include, for example, improving bond conditions using transversal wall connectors, mortar joint pointing, void filling, and confining stainless steel mesh embedded in a

Table 2. Properties of the Materials Considered in the Strengthening Strategies

\begin{tabular}{lcc}
\hline Material properties & $\begin{array}{c}\text { Strengthened } \\
\text { stone masonry }\end{array}$ & Steel tie-rods \\
\hline Modulus of elasticity, $E(\mathrm{MPa})$ & 560 & 210000 \\
Density, $\gamma\left(\mathrm{kN} / \mathrm{m}^{3}\right)$ & 19.60 & 20.00 \\
Poisson ratio, $\nu$ & 0.20 & 0.20 \\
\hline
\end{tabular}

plaster mortar layer [Fig. 6(c)]. This measure was modeled by increasing the elasticity modulus of masonry to $75 \%$, a value adopted from experimental studies (Costa 2002; Juhásová 2008)

Although the connection quality between walls is not evaluated in this study, the crucial importance of an efficient connection between the main structural elements (wall-floor, roof-wall, and wall-wall) in the global structural response is underlined.

\section{Natural Frequencies, Vibration Modes, and Model Calibration}

In situ dynamic identification testing was carried out with a seismograph, model GSR-16 (GeoSIG 1999), with the objective of estimating the natural frequencies that lead to the numerical model calibration (Júlio et al. 2008). Data acquisition was done for five different locations, as shown in Fig. 7, and for each, a five-minute 


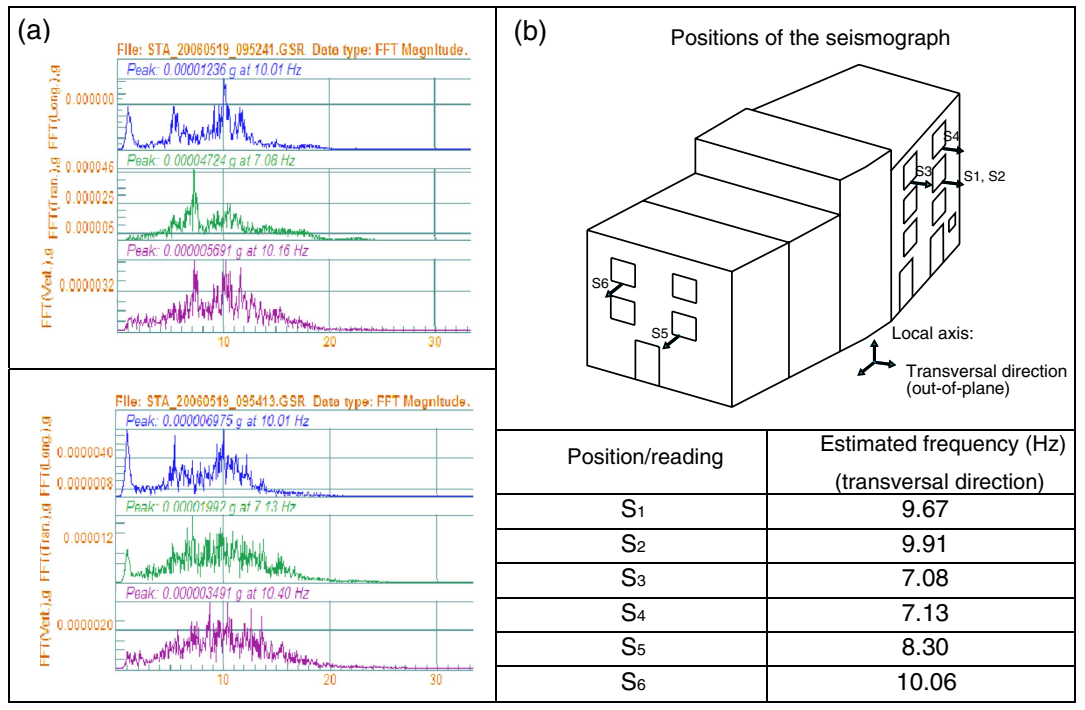

Fig. 7. Dynamic identification: (a) FFT for readings $S_{2}$ and $S_{3}$ in the 3 directions; (b) natural frequencies estimated by the power spectrums for the transversal direction of the walls

reading was acquired with 250 samples/s. The longitudinal, transversal, and vertical axes were defined in accordance with a local reference point.

With the data acquired for each position (input signals), the corresponding power spectra were calculated through a fast Fourier transformation (FFT) after previously applying a low and high filter and a Hanning time domain filter, using the strong motion detection software GeoDAS 2.17. Fig. 7 shows the power spectra obtained from the accelerograms acquired from Building $E_{4}$ (readings $S_{2}$ and $S_{3}$ ). Using the peak values of the spectra, the natural frequencies of the structure locally, specifically over the facade wall, are estimated.

Frequencies of 7.08 and $7.13 \mathrm{~Hz}$ (Table 3) were estimated from the accelerations measured at $S_{2}$ and $S_{3}$ in the transversal direction of the walls. These frequencies are associated with the vibration modes that involve an important transversal movement. Because of the complexity and dimensions of the building aggregate, it was only possible to analyze signals that allowed the identification of the local frequency of the facade wall of Building $E_{4}$ (readings $S_{3}$ and $S_{4}$ ).

Table 3. Comparison of the Measured and Calculated Frequencies

\begin{tabular}{lcc}
\hline Measured frequency $(\mathrm{Hz})$ & Calculated frequency $(\mathrm{Hz})$ & Error $(\%)$ \\
\hline 7.08 & 6.54 & -7.63 \\
7.13 & & -8.27 \\
\hline
\end{tabular}

Fig. 8 shows that for the three first modes of vibration of the structural model, the facade wall of Building $E_{4}$ has an important modal contribution attributable to the flexure of this wall to the out-of-plane direction.

The value adopted for the Young's modulus for the masonry walls, $E=1.75 \mathrm{MPa}$, is justified from three points of view: (1) the calibrated value is included in the range of the literature review for masonry walls with the same constitution and morphology; (2) local dynamic identification testing has been carried out; (3) results attained from the flat-jack testing (Vicente 2008) led to a mean value of $E_{0}=2 \mathrm{MPa}$, which approximates to the value calibrated and used for the numerical model.

\section{Results Analysis}

\section{Modal Analysis}

For any structural strengthening intervention, it is important to estimate the dynamic characteristics of the structure (natural frequencies and vibration modes). The strengthening solutions should avoid alteration of the natural frequencies and vibration modes, because their modification can lead to an increase in the seismic action, depending on the dominant period of the seismic record.

Approximately 65 to $70 \%$ of the total mass is attributable to the masonry walls. Therefore, the total mass of the structure does not change significantly with the strengthening Solutions A and B $\mathrm{z}$ (tie-rods or floor stiffening).

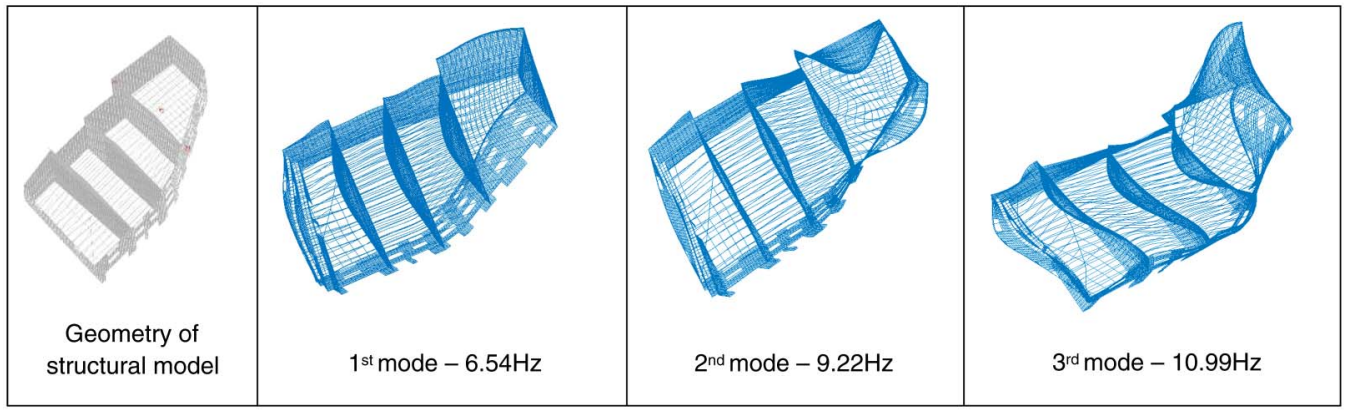

Fig. 8. Geometry of the structure and vibration modes 
Fig. 9 shows the first three modes of the original structure and each strengthening solution studied. From the comparative analysis of the natural frequencies estimated and the vibration modes, the following can be concluded:

- The first mode, for all the structural systems analyzed, essentially shows the translation along the longitudinal direction (X), revealing at the ground floor level a concentration of significant deformation demands attributable to the high number of openings in Direction X. The first mode shapes are evidence of the high vulnerability of some of the masonry walls to the out-of-plane movement (façade walls of Buildings $E_{1}$ and $\left.E_{4}\right)$;

- The retrofitting Solution A increases in-plane stiffness of the floors, reducing the out-of-plane deformation demands of the walls. Owing to the installation of tie-rods, the first natural frequency is increased by approximately $4.30 \%$ in comparison with the original structure;

- With retrofitting Solution B (floor stiffening), the first natural frequency was increased by $21.50 \%$. This strengthening technique provides the structure with a more integrated response of the whole building aggregate, considering the effectiveness of the diaphragm-wall connections (limiting the out-of-plane movement of the masonry walls);

- Masonry strengthening-Solution C-produces a similar first mode shape in comparison to the original structure. However for a stiffer structure, the natural frequency is increased by approximately $28 \%$;

- For Building $E_{4}$, the façade and gable-end walls suffer mostly from torsional movement because it has a diagonal direction in relation to the principal directions, $\mathrm{X}$ and $\mathrm{Y}$; and

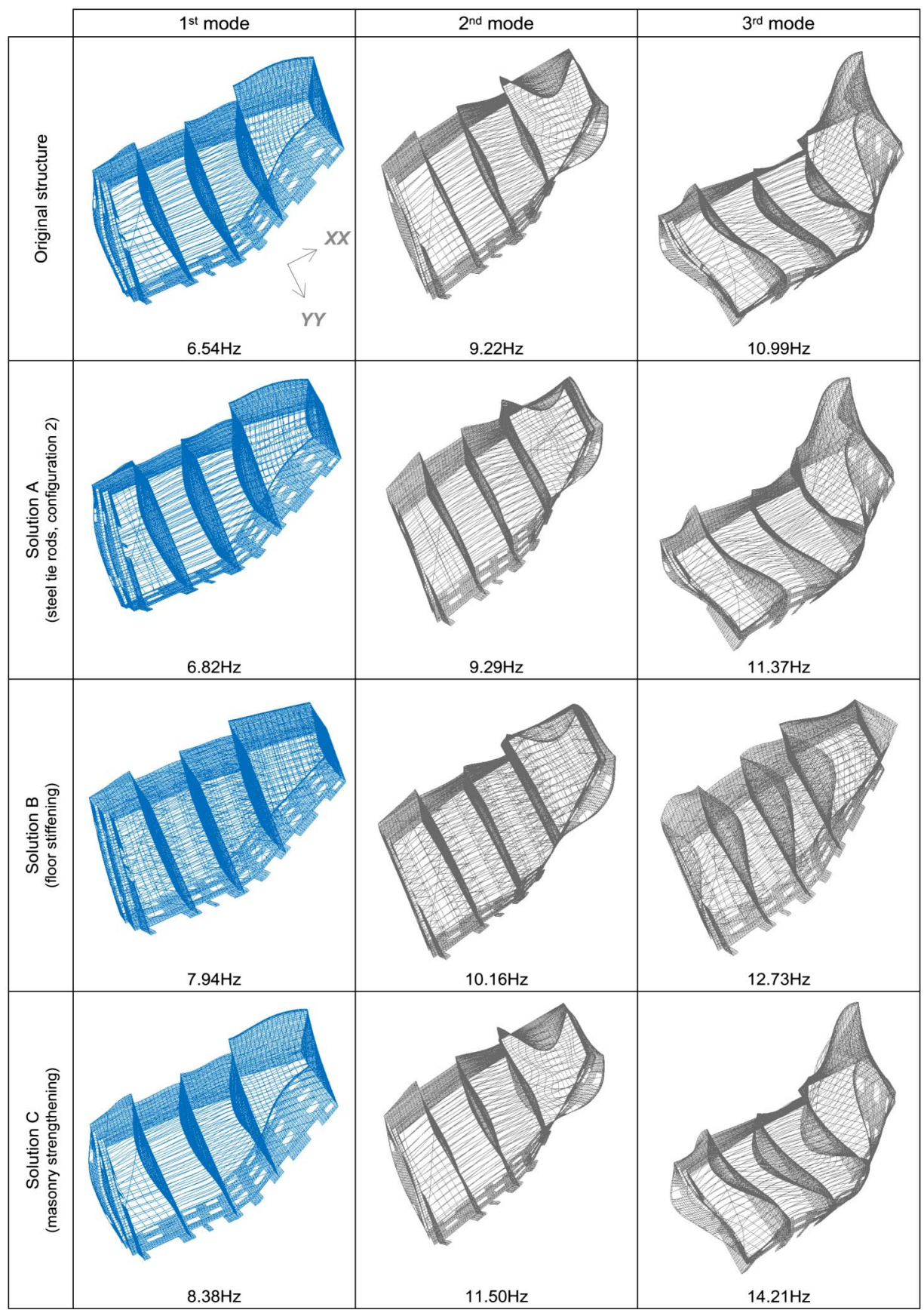

Fig. 9. Vibration modes and natural frequencies 
- For higher modes in general, the global torsional movement associated to the out-of-plane movements of the façades is considerable. However, the timber floor in-plane stiffening (Solution B) prevents the torsional movement verified in the other structural models.

\section{Influence of the Floor Diaphragm System}

The use of timber structured diaphragms and roofing systems importantly limits the structural response (Cardoso et al. 2005; Bento et al. 2005). To evaluate the influence of stiffness of the timber structures in the structural building response, the first natural frequency, corresponding to a global longitudinal mode shape, is compared for different values of the timber floor stiffness. The stiffness is reduced and increased 100 times (Fig. 10). From the results obtained, the following can be concluded:

- A reduction in timber structure stiffness reveals a lower impact on the first natural frequency of the structural system than with a stiffness increase (for example, comparing an equal increase and reduction, $k_{\text {mod }} / k_{\text {original }}=0.01$ and $k_{\text {mod }} / k_{\text {original }}=100$, in which $k_{\text {mod }}$ is the modified stiffness and $K_{\text {original }}$ is the original stiffness);

- Considering, for example, the degradation of the timber diaphragms' stiffness owing to poor conservation status (mechanical and physical properties), a reduced effect on the global behavior of the aggregate is verified; and

- Strengthening Solution B is equivalent to an increase in stiffness of the timber diaphragm system of approximately 30-fold (an increase of $21.50 \%$ compared to the first natural frequency).

\section{Interpretation and Analysis of the Causes of Cracking of Walls}

Once the numerical model has been calibrated and subjected to vertical loading $\left(1.00 \cdot G_{k}+1.00 \cdot Q_{k}\right)$, it is possible to obtain stress and strain values, allowing an understanding of the main causes that have led to the observed cracking.

Considering the vertical loading to which the building is subjected (self-weight and live load) and admitting a maximum tension stress for this type of limestone masonry of approximately $50 \mathrm{kPa}$, it was possible to identify the areas in which the cracking process will start, as shown in Figs. 11 and 12.

Analyzing Figs. 11 and 12, the influence of the vertical opening misalignment on the stresses in the masonry walls and consequently the origin of the observed diagonal cracking are clear. The preferential load path attributable to the opening distribution and stress concentration at the base of the walls and under the window openings, because of the more rigid stone panels used, can also

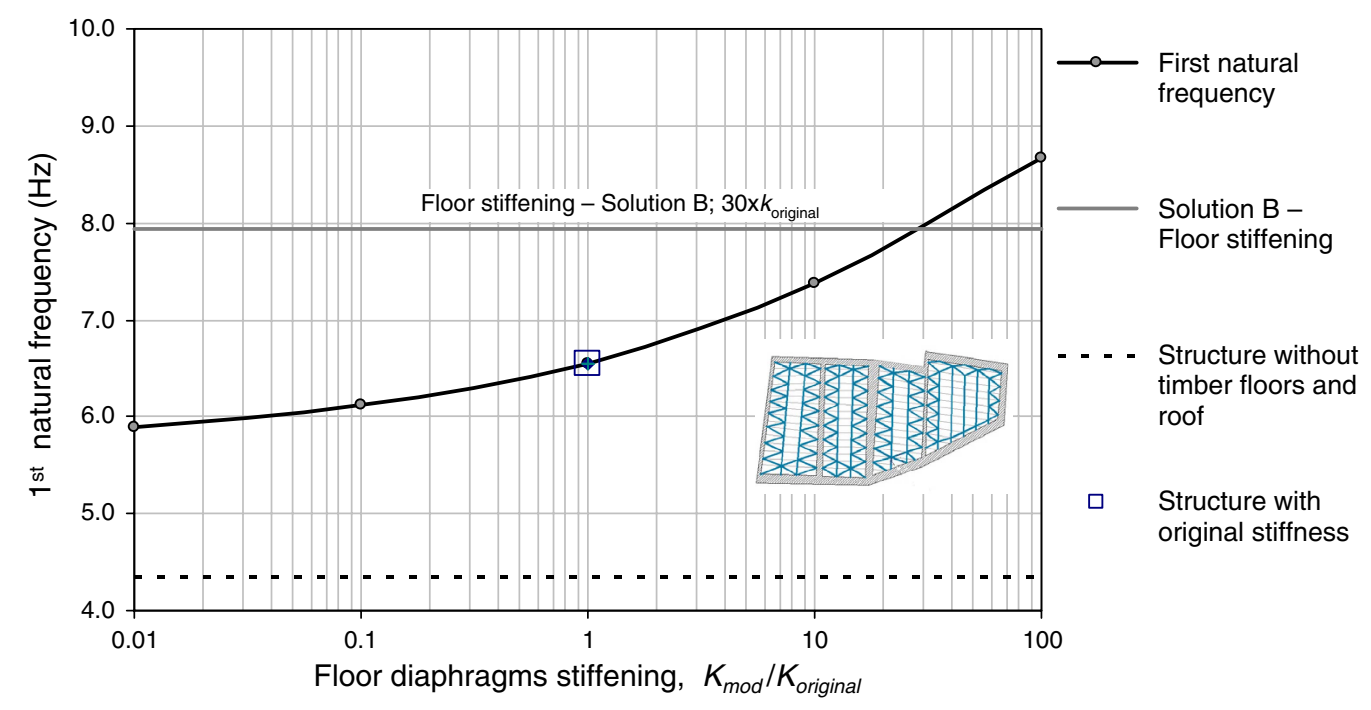

Fig. 10. Sensitivity of the structural response to the variation in the floor diaphragm stiffness
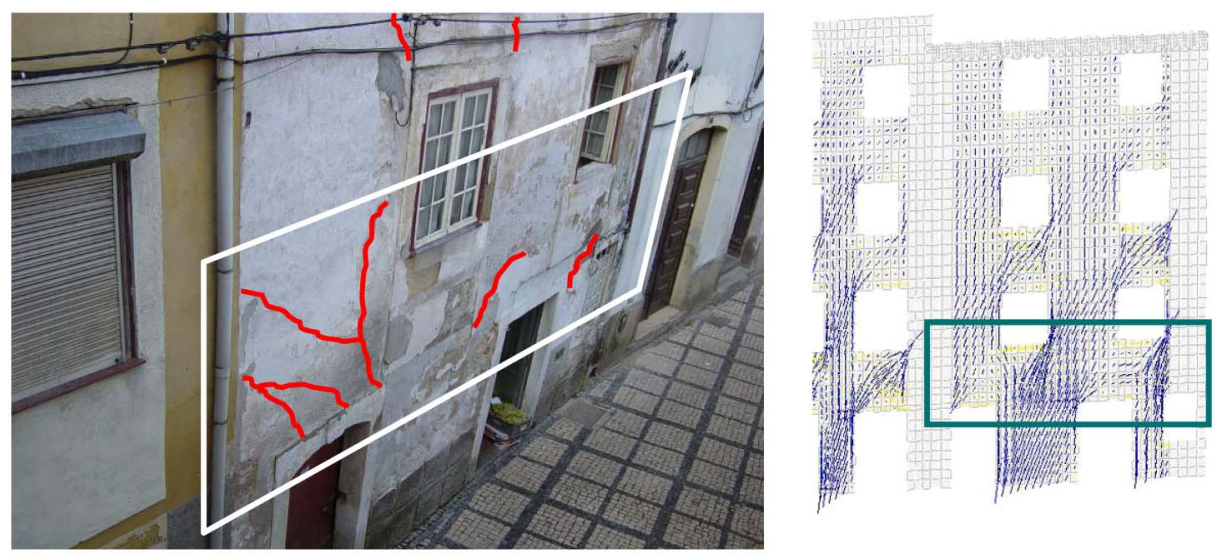

Principal stress directions

Fig. 11. Cracking observed and distribution of principal stresses for vertical loading conditions 

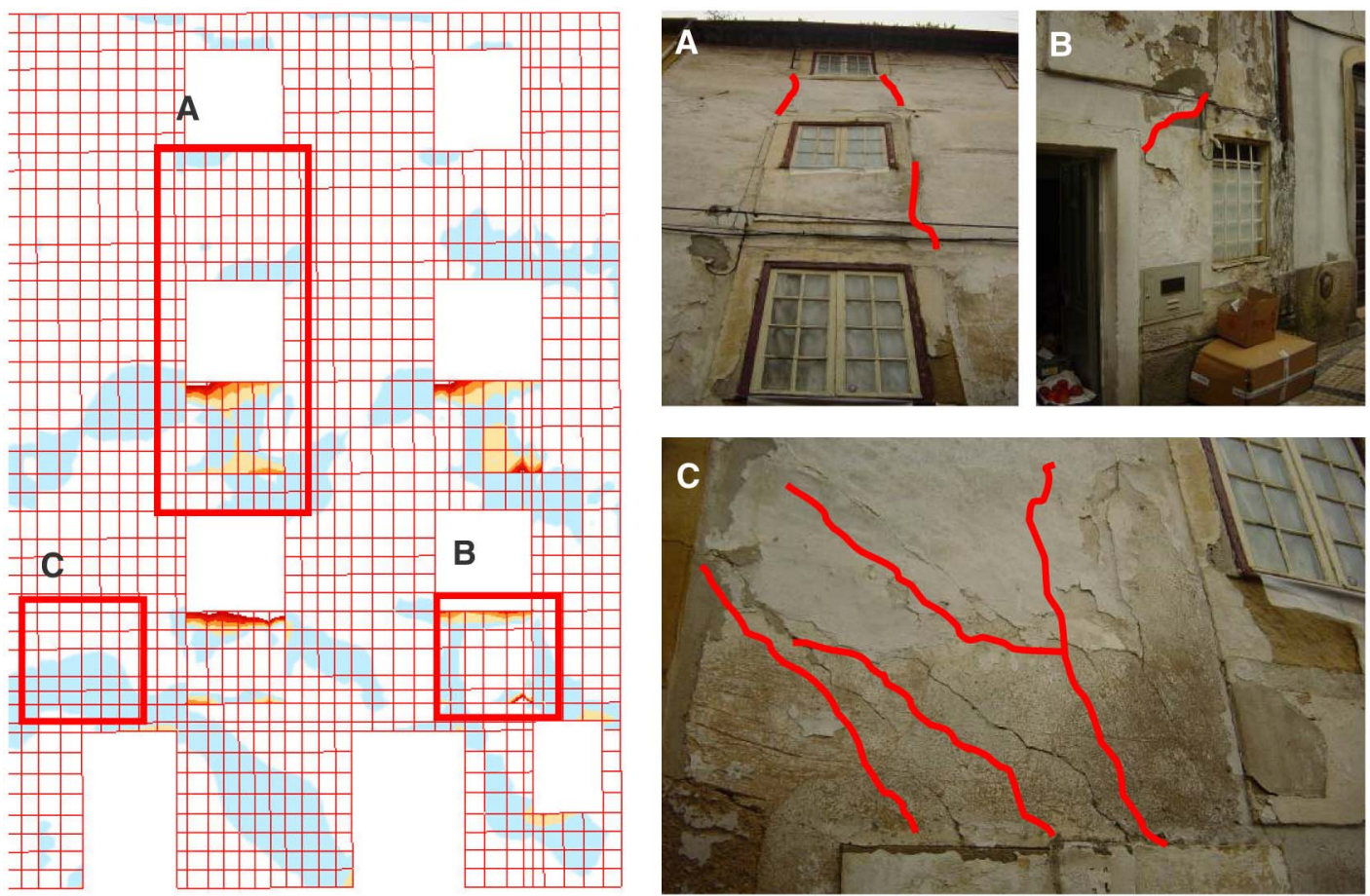

Fig. 12. Cracking and principal stress distribution for values superior to $50 \mathrm{kPa}$ for vertical loading conditions

be seen. Vertical cracking is observed between these stone panels and the irregular stone masonry, justified by the different behaviors of the two materials faced with thermal and moisture induced movements.

\section{Displacement and Drift Profiles}

The concentration of damage occurs near regions with highest deformation demand, as revealed by observations of damaged masonry constructions in recent earthquakes. To evaluate the efficiency of the modeled retrofitted solutions, the displacement profiles obtained numerically at crucial control nodes of the structure are presented and analyzed for the most significant five of the
16 control nodes selected in both directions ( $\mathrm{X}$ and $\mathrm{Y}$ ); namely, corner angles, top level of principal façades, and internal midwalls.

Analysis of Control Node P1 allows the efficiency of the simulated strengthening solutions in the reduction of the out-of-plane masonry façade wall movement in the northeast direction to be evaluated. The displacement profiles (Fig. 13) show that Strengthening Solution $\mathrm{C}$ is the most globally efficient, reducing the top-displacement by approximately $25 \%$.

Solution A (the floor stiffening retrofitting technique) demonstrates a better efficiency in comparison to all other retrofitting solutions with regard to the top-displacement reduction (approximately $36 \%$ ); however, globally it is not the most efficient in terms of the total wall height.
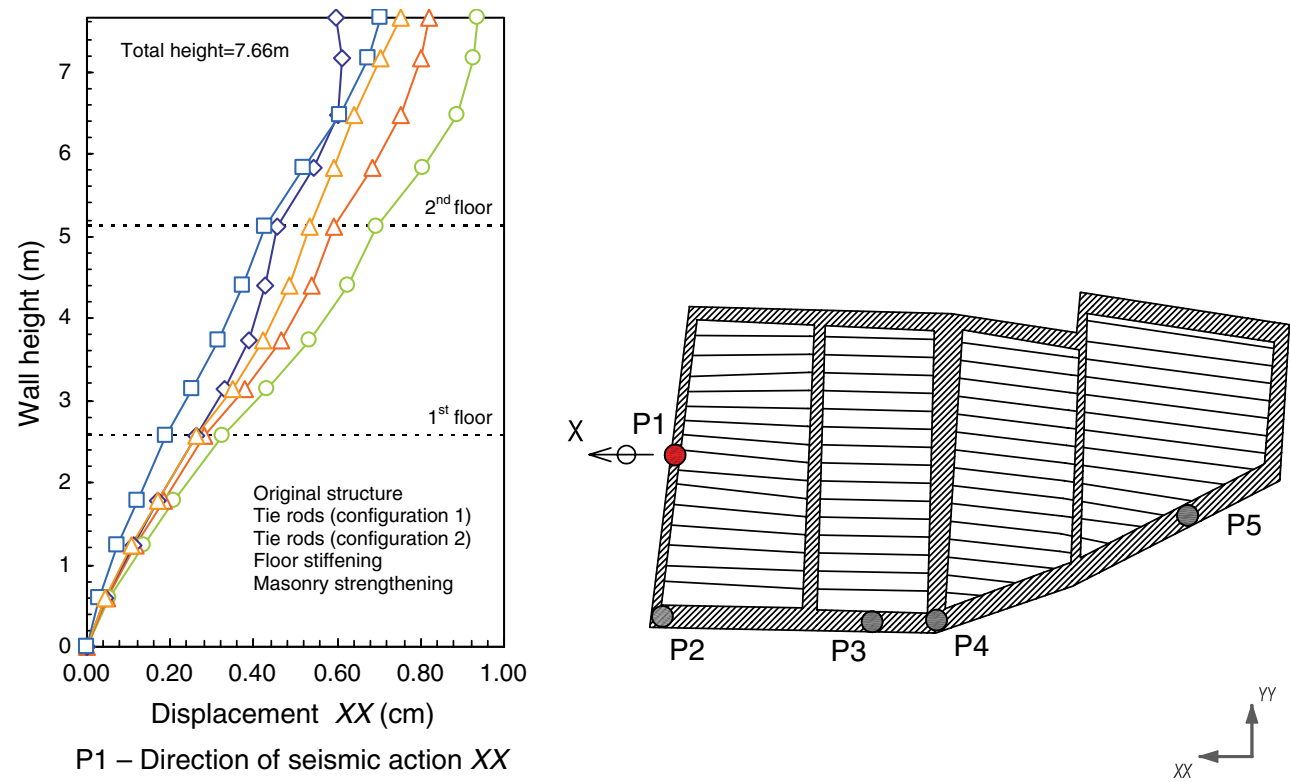

Fig. 13. Out-of-plane displacement profiles of the façade 

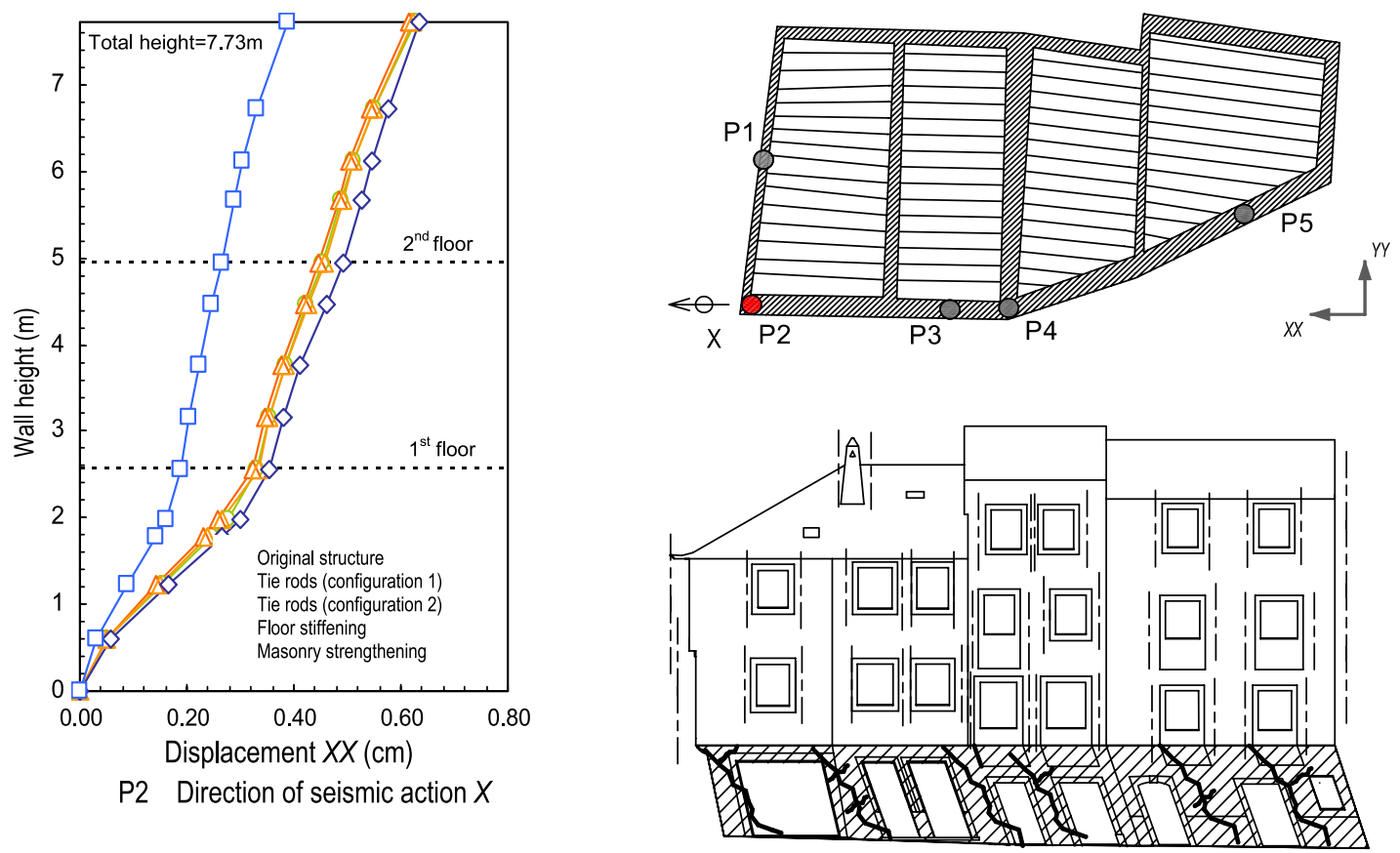

Soft-storey behaviour mechanism

Fig. 14. Displacement profiles of the building corner angle

The effectiveness of the tie-rod solution is lower in Solutions B and $\mathrm{C}$ in terms of top-displacement reduction; nevertheless, this solution is the least intrusive and costly compared to all other strengthening solutions analyzed, as will be discussed in the following. Of the two possible tie-rod configurations, Configuration 2 is $40 \%$ more efficient in the control of the top-displacement in relation to Configuration 1.
Fig. 14 shows the displacement profiles for Control Node 2 in the northwest direction; it is clear that only the masonry strengthening retrofitting solution significantly reduces the top-displacement demand (by approximately 37\%).

Considering that the purpose of the floor stiffening solution (Retrofitting Solution B) is to stiffen the timber floor structures globally, to control the out-of-plane deformation of the façade
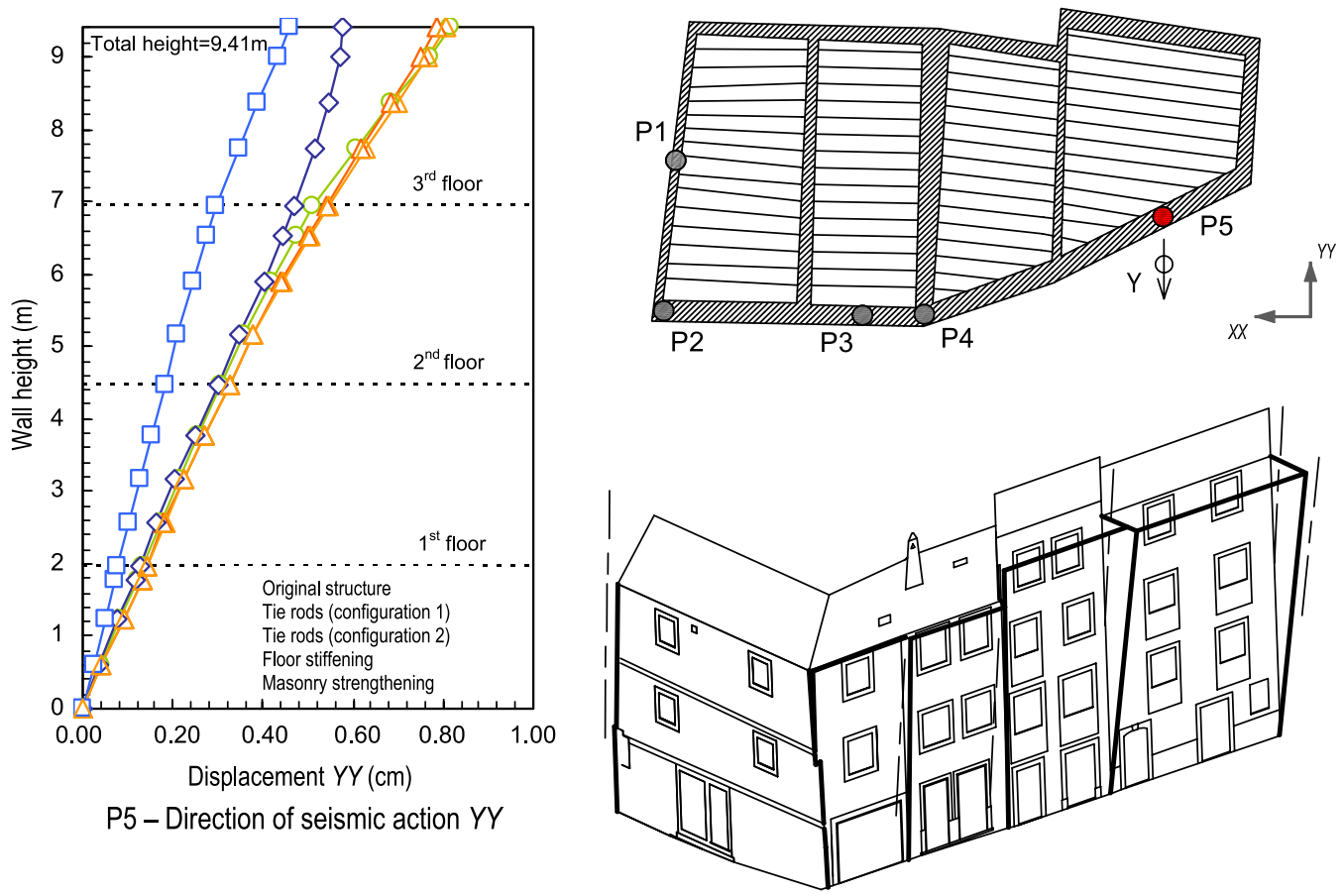

Out-of-plane deformation of the wall façades

Fig. 15. Displacement profiles of the façade 
walls, a slight negative effect in the in-plane deformation is observed, but it is insignificant taking into account the scale values, as shown in Fig. 14. In Solution A, the use of tie-rods shows no contribution to the control of the in-plane movement (Fig. 14).

For the original structure and the retrofitted solutions, the displacement profiles show a soft-story behavior mechanism at the ground floor level (displacement at this level represents more than $50 \%$ of the total top-displacement), revealing the vulnerability of this building aggregate to seismic action in the XX direction.

The analysis of the displacement profiles at Control Node P5 (Fig. 15) reveals that the use of tie-rods (retrofitting solution A) hardly reduces the top-displacement (approximately 4\%).

Timber structure floor stiffening (Retrofitting Solution B) prevents the out-of-plane movement, reducing the top-displacement by approximately $29 \%$ (Fig. 15). However, the efficiency of this solution is only possible if the stiffening retrofitting technique is applied to all timber floors, including the roofing structure. If this retrofitting technique is not carried out at all levels, even if it reduces the displacements at the level of the stiffened floor diaphragms, the irregularity in height of the stiffness will originate the amplification of displacements at the unstrengthened levels (the attic floor structure is normally a simple timber beamed diaphragm connected to the top of the masonry enclosure walls, which are extremely vulnerable at this level to the out-of-plane collapse mechanism).

The analysis of the displacement profile of Control Node P3 (Fig. 16) shows the soft-story behavior mechanism in the $\mathrm{XX}$ direction attributable to the high percentage of wall openings. In the other direction, for Control Nodes P2 and P4, the flexural behavior can be observed attributable to the extensive length of the internal walls, absence of openings, and orthogonality to the principal wall façades.
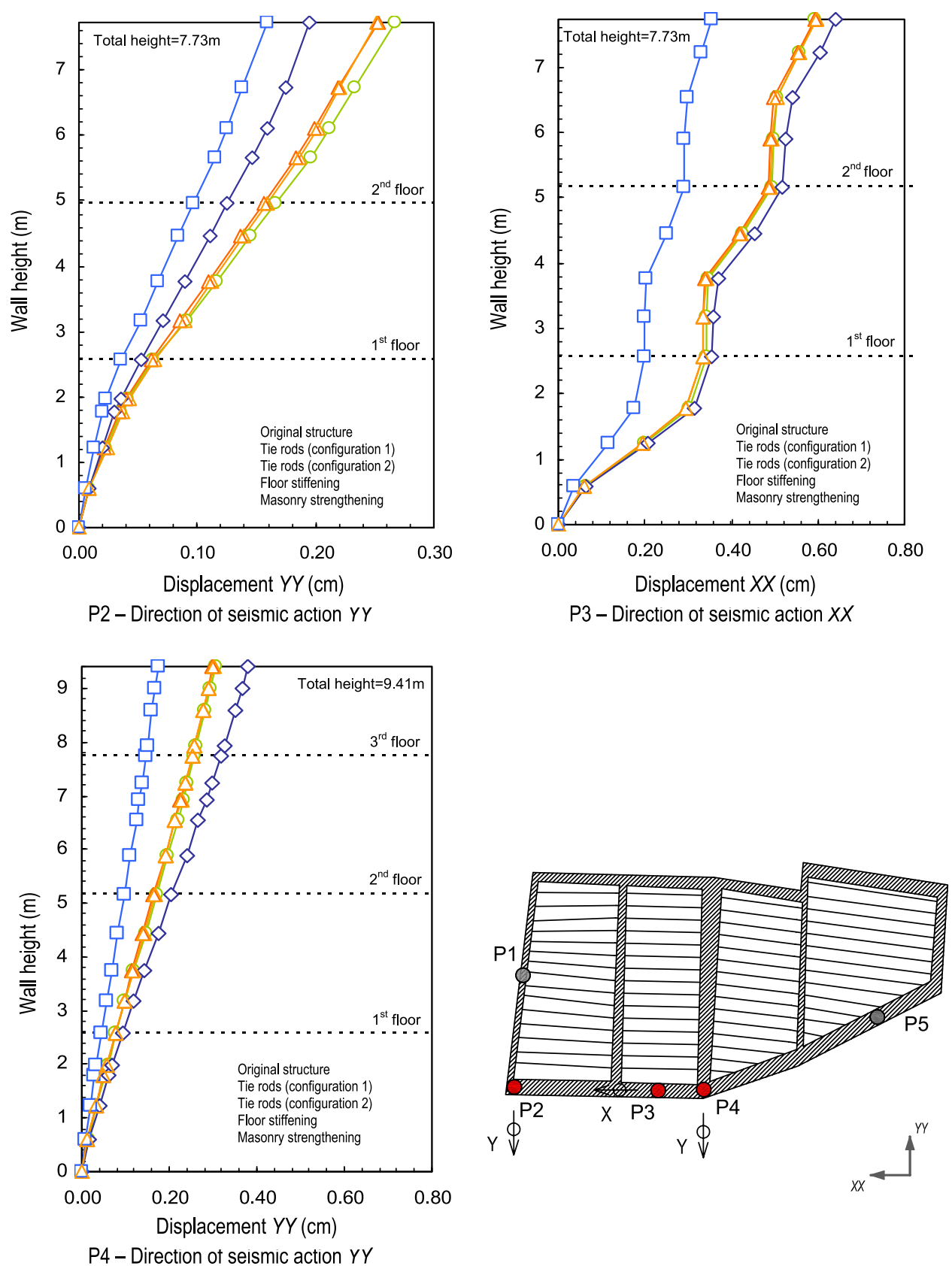

Fig. 16. Displacement profiles for Control Nodes P2, P3, and P4 
With regard to Control Nodes $\mathrm{P} 2, \mathrm{P} 3$, and P4, the most efficient retrofitting solution in the reduction of the displacements is masonry strengthening (Solution $\mathrm{C}$ ), attaining a reduction in the top-displacement of approximately $50 \%$ on average.

The floor stiffening solution of the timber structures (Solution B), proposed as a retrofitting solution, aims to stiffen the floor diaphragms and consequently reduce the out-of-plane movement, leading to a better redistribution of the deformation demands of the load-bearing masonry enclosure walls that are efficiently connected. Figs. 14 and 16 show that a slight aggravation of the displacement is registered for the Control Node P2, P3, and P4 displacement profiles; however, this can eventually be a concern if the masonry is locally feeble and presents a high risk of out-of-plane instability.

Considering the low to moderate level of seismic action in this study, Control Nodes P1, P2, and P5 were selected to analyze the interstory drift. Up front, none verify the first level of in-plane deformation, which was defined as immediate occupancy (IO), with a drift-limit of $0.10 \%$ (FEMA-356 2000), and slight damage can be expected (hairline cracking). This is the only performance level evaluated because the linear elastic model does not allow security for the evaluation of other levels of performance and more severe damage states associated with the nonlinear behavior regime.

Fig. 17 shows that Retrofitting Solutions B and C (floor stiffening and masonry strengthening) reduce the interstory drifts for Control Nodes P1 and P2 below the IO performance level driftlimit. The drift profile for Control Node P2 clearly reveals the vulnerability of the ground floor level to seismic action in the $\mathrm{XX}$ direction. Only Retrofitting Solution C (masonry strengthening) presents an important reduction in the interstory drift and consequently prevents the occurrence of the soft-story mechanism.

The interstory drift profile for Control Node P5 (Fig. 17) shows that the masonry strengthening solution is most efficient and is the exception to the verification of the IO performance level. However, the timber floor in-plane stiffening solution is found to significantly reduce the in-plane deformation at higher floor levels for the load-bearing masonry enclosure walls, which are usually more slender and subjected to a lower compression stress state and more vulnerable to lateral loading. FEMA-356 (2000) does not indicate out-of-plane interstory drift limits for unreinforced masonry walls; however, it indicates geometrical control, height-to-thickness ratio, and damage state control based on floor accelerations and velocities.

\section{Damage Levels: Stress Analysis}

The stress concentration at the ground floor also demonstrates the demand concentration at this level (Fig. 18). High stress concentration exceeding stone masonry tensile and shear strengths leads to cracking, and consequently, stiffness reduction can start and a soft-story mechanism can develop.

The stress concentration in the vicinity of the openings is slightly reduced in strengthened models, particularly with the floor stiffening solution, in which the reduction in the peak stresses is approximately $30 \%$, and the stress distribution throughout the front wall façade is more uniform. Because the stone panels under the window openings are very stiff compared with regular stone masonry, the concentration of tensile stress induces local damage in these elements. The misalignment of façade wall openings in Building $E_{4}$ aggravates the load stress path and leads to the aggravation the damage concentration.

Assuming that masonry strengthening increases the tensile strength proportionally to the elastic modulus, the damaged area (Fig. 18(e)) is significantly reduced.

\section{Improvement of the Structural Integrity: Cost-Benefit Analysis}

To compare the efficiencies of the retrofitting solutions studied, a indicator was used that would take into account the reduction of the horizontal displacement at the top level of the walls, at Control Nodes P1, P2, P4, and P5, and the cost of each retrofitting solution. Control Nodes P1 and P5 were selected to evaluate the efficiency of the solutions that control the out-of-plane deformations of the load-bearing walls, and Control Nodes P2 and P5 were selected to evaluate the efficiency of the in-plane deformation of the loadbearing walls.

The estimated costs of the retrofitting solutions were obtained from budgets solicited from specialized contractors in rehabilitation and retrofitting work who are familiar with the strengthening

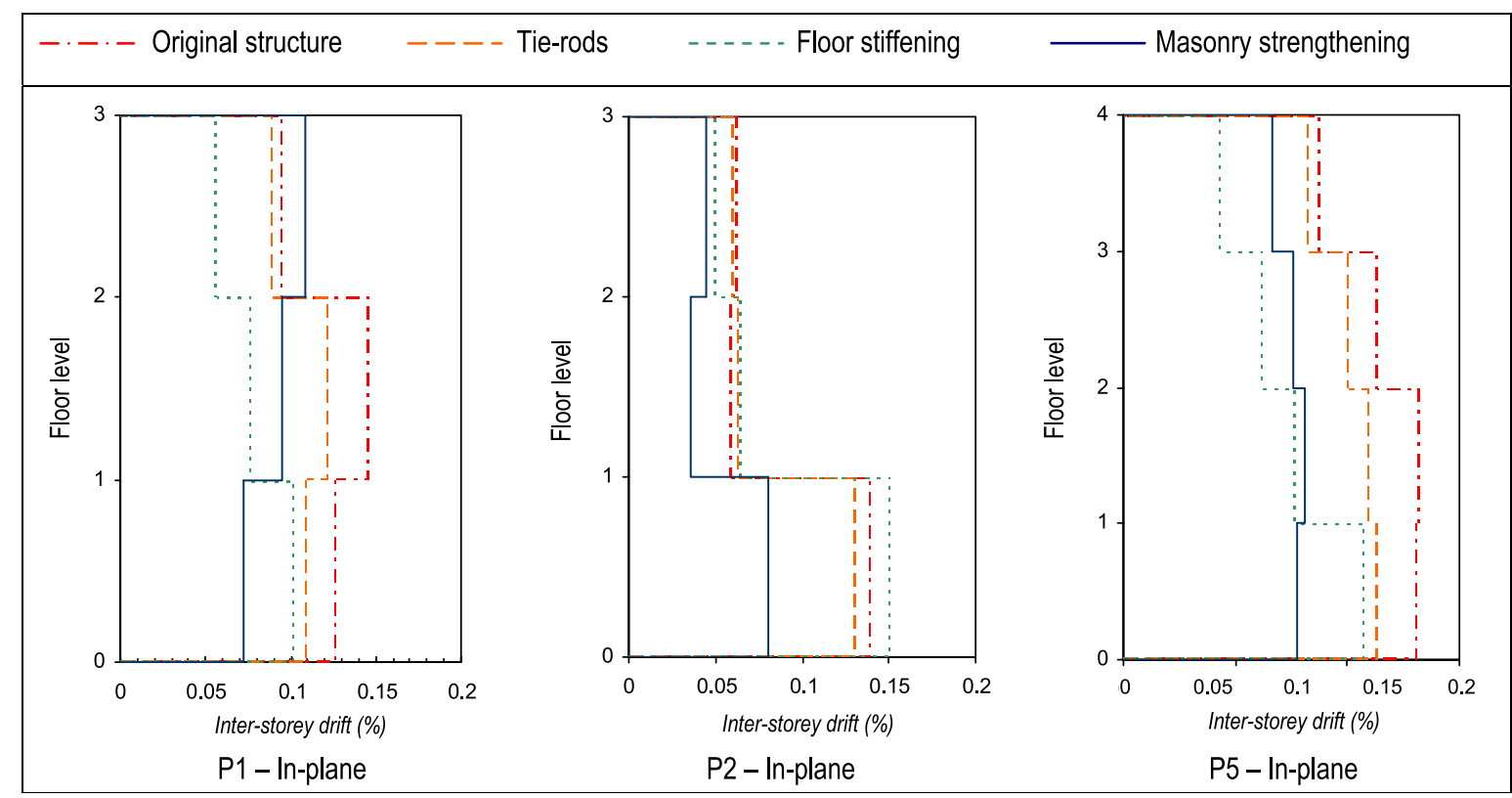

Fig. 17. Interstory drift profiles for Control Nodes P1, P2, and P5 


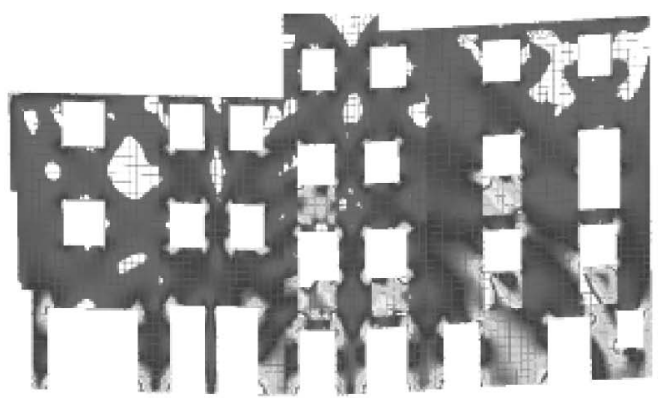

(a) Original structure

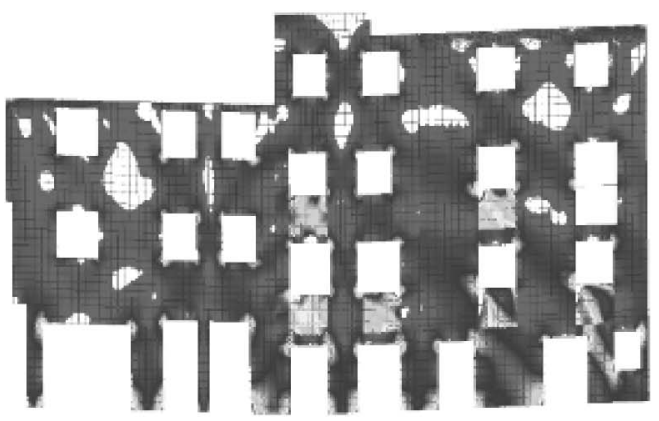

(c) Floor stiffening (Solution B)

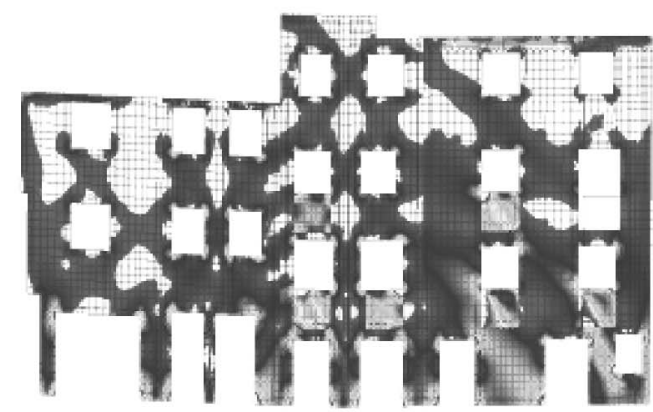

(e) Masonry strengthening (Principal stress > $0.05 \times 75 \%$ ) (Solution C)

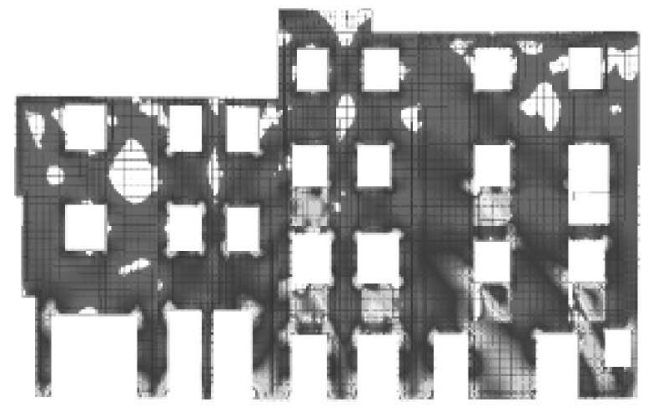

(b) Tie-rods (Solution A)

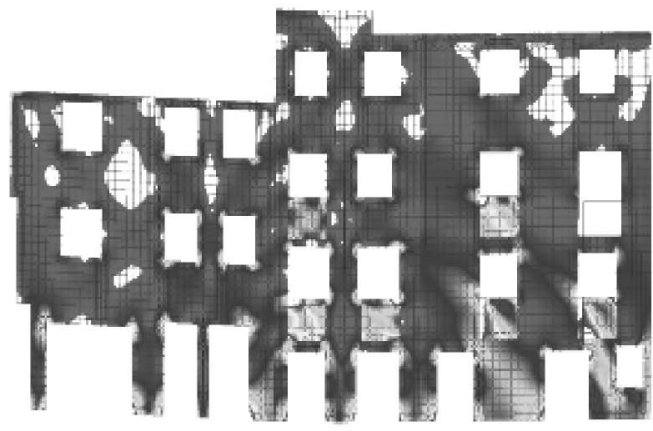

(d) Masonry strengthening (Solution C)

Maximum principal stress $\sigma_{1}(\mathrm{MPa})$

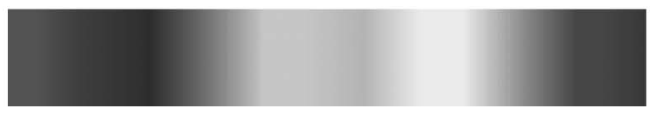

0.05

Fig. 18. Maximum principal stress distribution: (a) original structure; (b) tie-rods (Solution A); (c) floor stiffening (Solution B); (d) masonry strengthening (Solution C); (e) masonry strengthening, principal stress $>0.05 \times 75 \%$ (Solution $\mathrm{C}$ )

Table 4. Patrimonial Value of the Building Aggregate and Cost of the Three Retrofitting Solutions

\begin{tabular}{lrc}
\hline Retrofitting solution & Cost & Retrofitting action cost/Patrimonial value of the aggregate $(\%)$ \\
\hline Solution A-Steel tie-rods (Configuration 2) & $8,000.00 \&$ \&euro; & $2 \%$ \\
Solution B-Floor stiffening & $48,000,00 \&$ \&euro; & $12 \%$ \\
Solution C-Masonry strengthening & $80,000,00 \&$ \&euro; & $20 \%$ \\
Estimated patrimonial value of the aggregate & $400,000.00 \&$ \&euro; & \\
\hline
\end{tabular}

techniques proposed. The budgeting allowed a high price dispersion to be attained; however, mean values were adopted, as shown in Table 4 . The patrimonial value of this aggregate is evaluated as 400,000.00\&euro; .

Fig. 19 shows the reduction of the deformation demand at the top of the external load-bearing masonry walls for the control nodes selected (P1, P2, P4, and P5) as a function of the ratio between the cost of the retrofitting solution and the patrimonial value of the aggregate studied. The solution using tie-rods represents only $2 \%$ of the global patrimonial value, although its efficiency in the control of the in-plane and out-of-plane deformation is very modest. The stiffening of the timber floor diaphragms is shown to be the most positive in the control of the out-of-plane deformation demand (Nodes P1 and P5). However, this solution originates a negative effect over the deformation demands of the walls in their in-plane direction (Nodes P2 and P4). Solution C, masonry strengthening, presents itself globally as the most efficient solution in the reduction of the deformation demands, but is the most costly and intrusive (approximately $20 \%$ of the aggregate value).

Comparing Solution B (floor stiffening) and Solution A (masonry strengthening), both significantly reduce the deformation demands in the out-of-plane direction of the stone load-bearing masonry walls (Fig. 19). With regard to the deformation control of the walls in the in-plane direction, both solutions are less effective 


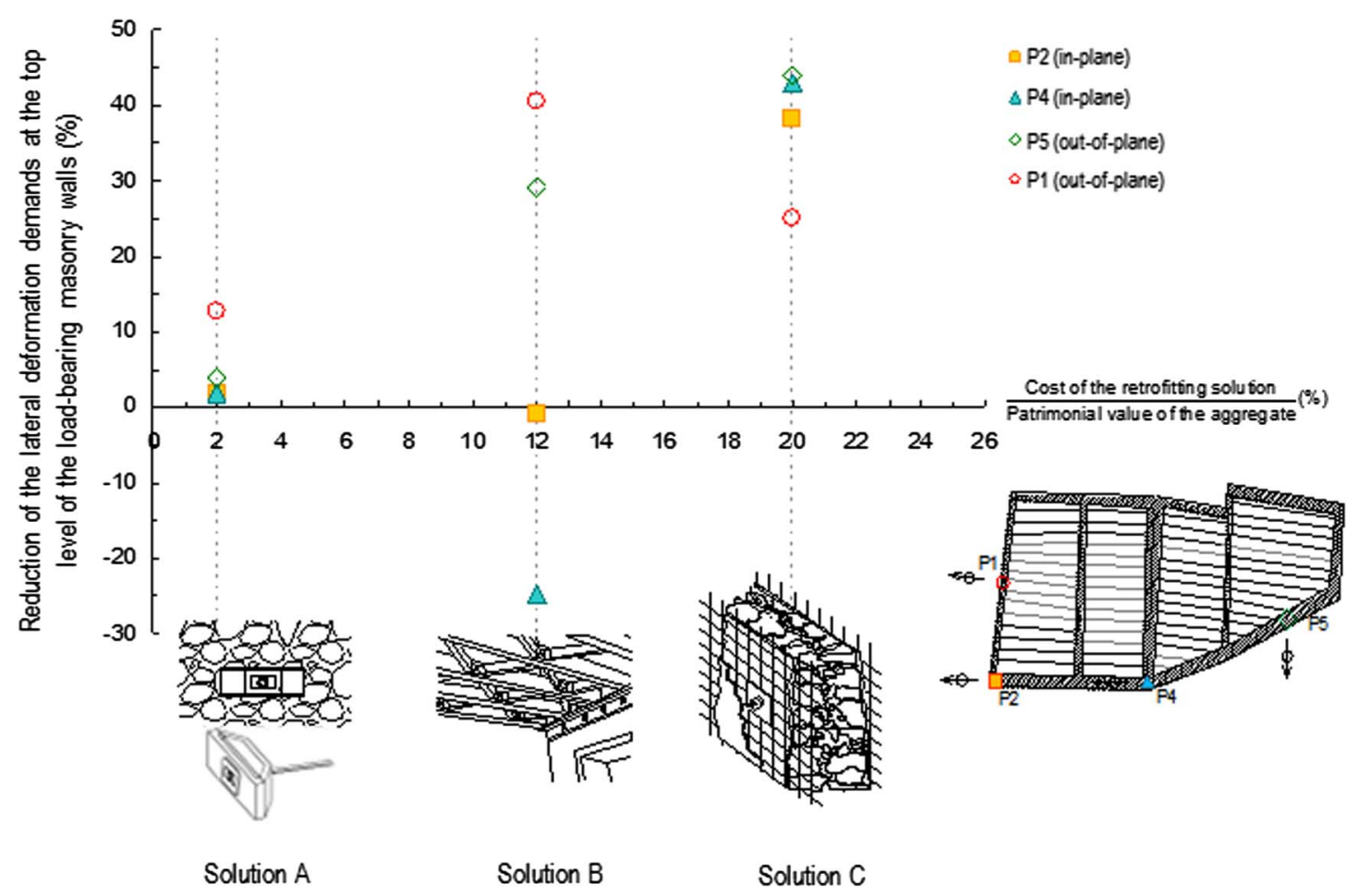

Fig. 19. Efficiency of the retrofitting solutions

than for the out-of-plane restraining of the deformation; however, differences in the in-plane deformation control among solutions are relatively small, taking into account the scale of values (Mallardo et al. 2008).

Therefore, considering that the deformations in the out-of-plane direction are of greater amplitude and that it is intended to prevent probable out-of-plane collapse mechanisms, it is concluded that for optimization in terms of the binomial cost-benefit (Varum et al. 2006), stiffening of the timber floor diaphragms (Retrofitting Solution C) is the most recommendable solution.

\section{Final Comments and Conclusions}

The present case study illustrates the use of a finite-element tool to determine the most effective retrofitting strategies for this case study. The seismic response of old traditional masonry buildings is very dependent on the aggregate organization and constructive building features.

This research has allowed seismic performance to be better understood, and has presented and discussed the efficiency of possible retrofitting solutions. The numerical model carried out for a representative building aggregate of the old city center of Coimbra states some final essential comments about retrofitting solutions.

The high number and dimensions of openings at the ground floor greatly influence the deformation of wall façades and the stress concentration for earthquakes acting in the longitudinal direction. Interstory drifts are rather high at ground level, which can originate a soft-story mechanism. Enlargement of openings or suppression of masonry walls at ground floor, for example, to install commercial open spaces or garages is an inadequate practice in old buildings that should not be overlooked.

The asymmetry of total area of openings between the front and posterior façades of the buildings induces a global torsion of the group of buildings modeled. However, it is recognized that the global behavior of the overall aggregate attenuates the torsional effects.

The masonry walls are very vulnerable to out-of-plane deformations. The connection to the timber floor structures and use of orthogonal walls are important measures to reduce their vulnerability to the out-of-plane collapse mechanisms, and are particularly important for higher floor levels, as observed in the displacement profiles.

According to the retrofitting techniques studied, masonry strengthening is found to be the most efficient technique in reducing the displacements (out-of-plane and in-plane). Increasing the diaphragm stiffness can be an effective retrofitting solution to improve the global behavior of old masonry buildings. However, when this strengthening technique is not applied at all floor levels, the deformation demands at the upper stories can be larger than for the original nonstrengthened structure. Tie-rods can be efficient in restraining the out-of-plane deformations of masonry walls. As expected, numerical results indicate that they do not contribute significantly to the in-plane response. Tie-rods are especially effective at roof level and their configuration is fundamental, as proven by a comparison of the results among different configurations.

The studied strengthening techniques were designed respecting the original conception of the building. Nevertheless, economical cost analysis and the intrusion level of these schemes must be considered. Stone masonry strengthening and timber floor stiffening are normally costly and intrusive measures, and imply additional costs for the temporary rehousing of residents. A combination of the studied strengthening actions could probably be the most effective strengthening scheme, using, for example, floor stiffening at all levels, roof tie-rods, and masonry strengthening exclusively at ground floor level.

Numerical modeling of historical constructions must be seen as a valuable tool in support of the structural upgrading design and the definition of suitable and efficient interventions. The linear elastic material assumption is a good first iteration to understand global structural seismic behavior. Masonry structures have a nonlinear 
behavior which can introduce cracking that leads to energy dissipation, which has the potential to significantly change the deformation behavior and stress distributions of the structure. Therefore, future nonlinear dynamic analysis is necessary to understand cracking patterns and improve the knowledge of the effectiveness of the retrofitting strategies.

The conclusions drawn in this unique case study are valid in understanding the overall behavior tendencies of old masonry structures, and therefore, generalization of these conclusions for historical masonry constructions is complex and cannot be applied generally without considering the aggregate effect, geometry, and building configuration from case to case. Experimentation, monitoring, and observation are complementary actions that should be developed parallel to the numerical analyses.

\section{Acknowledgments}

The authors would like to thank the task group of the Coimbra City Renewal Process for granting the CAD drawings and building information used in this paper.

\section{References}

Bento, R., Lopes, M., and Cardoso, R. (2005). "Seismic evaluation of old masonry buildings. Part II: Analysis of strengthening solutions for a case study." Eng. Struct., 27(14), 2014-2023.

Cardoso, R. (2002). "Seismic vulnerability of old masonry structuresApplication to a Pombalino building." M.Sc. thesis, Structural Engineering, Instituto Superior Técnico, Lisbon, Portugal (in Portuguese).

Cardoso, R., Lopes, M., and Bento, R. (2005). "Seismic evaluation of old masonry buildings. Part I: Method description and application to a case-study." Eng. Struct., 27(14), 2024-2035.

Carvalho, E. (2007). "Mitigação do risco sísmico em Portugal, O., and papel do LNEC: Encontro sobre redução da vulnerabilidade sísmica do edificado em Portugal." Sociedade Portuguesa de Engenharia Sísmica and GECoRPA (in Portugese).

CEN. (2004). Eurocode 8: Design of structures for earthquake resistance -Part 1: General rules, seismic actions and rules for buildings, European Committee for Standardisation, Brussels, Belgium.

Costa, A. (2002). Determination of mechanical properties of traditional masonry walls in dwellings of Faial Island, Azores, Earthquake Engineering and Structural Dynamics, 31, 1361-1382.
Farinha, J. S. B., and Reis, A. C. (1998). Tabelas técnicas, Edições Técnicas Lisboa Lda., Lisbon (in Portugese).

FEMA-356. (2000). Prestandard and commentary for the seismic rehabilitation of buildings, American Society of Civil Engineers and Federal Emergency Management Agency, Washington, D.C.

GeoSIG [Computer Software]. (1999). Switzerland, GSR.

Giuffrè, A. (2000). Sicurezza e Conservazione dei Centri Storici Il caso Ortigia, Editore Laterza \& Figli Spa, Rome-Bari (in Italian).

Juhásová, E., Sofronie, R., and Bairrão, R. (2008). "Stone masonry in historical buildings-Ways to increase their resistance and durability." Eng. Struct., 30(8), 2194-2205.

Júlio, E., Rebelo, C., and Dias-da-Costa, D. (2008). "Structural assessment of the tower of the University of Coimbra by modal identification." Eng. Struct., 30(12), 3468-3477.

Mallardo, V., Malvezzi, R., Milani, E., and Milani, G. (2008). "Seismic vulnerability of historical masonry buildings: A case study in Ferrara." Eng. Struct., 30(8), 2223-2241.

Pagaimo, F. A. L. (2004). "Mechanical characterization of old masonries. Case study of the historical town of Tentúgal." M.Sc. thesis, Civil Engineering, Faculdade de Ciências e Tecnologia da Universidade de Coimbra, Coimbra, Portugal (in Portuguese).

Robot Millennium v17.5. Structural analysis and design software, User manual, ISS, San Francisco.

Varum, H., and Rodrigues, H. (2005). "Avaliação do comportamento estrutural da torre medieval de Vilharigues-Vouzela." Congreso de Métodos Numéricos en Ingeniería 2005, Sociedad Española de Métodos Nunéricos en Ingenieria (SEMNI), Granada, Spain (in Portuguese).

Varum, H., Vicente, R., Rodrigues, H., and Silva, J. A. R. (2006). "Seismic evaluation of old masonry buildings: Performance and strengthening." Proc., 8th Int. Conf. on Computational Structures Technology, CST2006. Las Palmas de Gran Canaria, Spain, B. H. V. Topping, G. Montero, and R. Montenegro, eds., Civil-Comp Press, Stirlingshire, UK, 12-15.

Vicente, R. S. (2008). "Strategies and methodologies for urban rehabilitation interventions. The vulnerability assessment and risk evaluation of the old city centre of Coimbra." Ph.D. thesis, Univ. of Aveiro, Aveiro, Portugal (in Portuguese).

Vicente, R. S., Silva, J. A. R., and Varum, H. (2005a). "Strategies for building pathology reports in a urban rehabilitation process." 10DBMC Int. Conf. on Durability of Building Materials and Components, Lyon, France.

Vicente, R. S., Varum, H., and Silva, J. A. R. (2005b). "Seismic vulnerability assessment of buildings in the old city centre of Coimbra." Int. Conf.: 250th Anniversary of the 1755 Lisbon Earthquake, Laboratório Nacional de Engenharia Civil (LNEC), Lisbon, Portugal. 